\title{
Posterior Lumbar Interbody Fusion in Degenerative Lumbar Spine Disease and Risk of Adjacent Segment Disease
}

\author{
IJAZ HUSSAIN WADD, ASIF SHABIR, LIAQAT MEHMOOD AWAN, SYED MOHSIN \\ AJMAL, HUMAIRA MUSHTAQ, RIZWAN MASOOD BUTT \\ Punjab Institute of Neurosciences (PINS), Lahore General Hospital, Lahore - Pakistan \\ DOI: DOI 10.36552/pjns.v24i2.439
}

\begin{abstract}
Objective: To determine the chances of adjacent segment disease (ASD) and risk factors after posterior lumbar interbody fusion (PLIF).
\end{abstract}

Material and Methods: The 110 patients of both genders with degenerative lumbar instability at L4/5 level were included in my study. We did PLIF in all our patients and followed our patients for one year. The following parameters were measured: the degree of lumbar lordosis, the degree lumbosacral angle, the disc space height and their dynamic angulation and the displacement of L3 over L4. We checked the outcome with the help of the Japanese orthopedic association (JOA) and Oswestry disability index (ODI). We divided the patients into groups $A$ and B; group A includes patients with progression of degeneration at the proximal level (L3-LA), while group B with no progression of disease at proximal level.

Results: The 86 patients (78.18\%) were in group A, and 24 patients $(21.88 \%)$ were in group B. There were no significant difference in radiological parameters of both groups; lumbosacral angle of lordosis, L3 laminar inclination angle, preoperative degenerative changes at proximal level, L4-L5 lordosis and BMD before surgery. The clinically and statistically significant differences were of the age of the patients falling in two groups. We found that at the completion of study ODI and JOA were not significantly different in both groups $(P>0.05)$.

Conclusion: Degenerative lumbar disease is an age related disease with no significant effect of radiological degenerations on the final outcome of our patients. No other possible risk factor has a significant effect on outcome.

Keywords: Lumbar Spinal Fusion and Fixation, Adjacent Segment Disease, Outcome of Patients.

Abbreviations: PLIF: Posterior Lumbar Interbody Fusion. JOA: Japanese Orthopedic Association. ODI: Oswestry Disability Index.

\section{INTRODUCTION}

Most common cause of low backache and disability is a degenerative lumbar spine disease. Many spine surgeons are working on it and many treatment options (medical and surgical) are available for this. Lumbosacral spine fixation and fusion is mostly performed procedure for this disease. Multiple surgical techniques are being used to fuse the lumbar spine by the spinal surgeon, i.e., posterior fixation with or without lumbar interbody fusion (PLIF). Spinal fixation and fusions changes the biomechanics of spine $^{1-2}$. PLIF gives strong fusion with instrumented fixation at the cost of increasing movements at adjacent level ${ }^{3}$. Age is a significant risk factor for degeneration of the spine and adjacent segment disease $^{4}$. Still, there are controversies that whether spinal fusion leads to adjacent segment disease or not. Battie et $\mathrm{al}^{5}{ }^{5}$ in their study reported that adjacent segment degeneration is a natural disease process and has no definite association with spinal fusion. Older age is a risk factor for radiological degeneration of the spine $^{6}$. Lee et al proved that interbody device can lead 
to adjacent segment disease ${ }^{7}$.Fusion and fixation of the lumbar spine are the most commonly performed procedure, but it's not without complications. Lad et al, proved that increase rate of complications for laminectomy $4.8 \%$ vs. $8.3 \%$ for instrumented fusions and at 5 years reoperation rate was $10.6 \%$ with laminectomy versus $18.4 \%$ when spinal instrumentation added $^{8}$. Spinal fusion is the most commonly performed procedures for degenerative lumbar spine ${ }^{9}$. So we conducted the study at our centre to see the association of fixation and fusions with adjacent segments degenerations.

\section{MATERIALS AND METHODS}

\section{Study Design}

Prospective observational study. We conducted this study at Punjab institute of neurosciences (PINS), Lahore from June 2015 to June 2018.

\section{Inclusion Criteria}

we included 110 patients with lower back pain due to radiological proven grade 1 and 2 instability at L4 L5. We did PLIF with Titanium cages filled with autologous bone followed by Transpedicular fixation. We included 52 males and 58 females and our patients mean age was 55.8 years (range $35-70$ years). We followed all our patients for 1 year.

\section{Exclusion Criteria}

The patients with multilevel degenerative lumbar disease and disease proximal to L4 - 5 and with comorbid conditions and not fit for anesthesia were excluded from our study.

\section{Data Collection}

The following parameters were measured in all patients on pre-operative $\mathrm{X}$-ray and entered on a proforma; degree of lumbar lordosis, degree of lumbosacral angle, the disc space height and their dynamic angulation and the displacement of L3over L4.

\section{Data Analysis}

The adjacent segment disease was if disc space height is less than $3 \mathrm{~mm}$ with dynamic angulation more than 5 degrees with more than $3 \mathrm{~mm}$ displacement of L3 over L4. The JOA score and ODI were used for outcomes measurements. All entered data was analyzed with SPSS version 22 and t test was used. $\mathrm{P}$ value $<0.05$ was taken as significant.

\section{RESULTS}

\section{Gender Incidence}

At conclusion of our study 86 patients $(78.18 \%)$ were in group A and 24 patients $(21.88 \%)$ were in group B.

\section{Age Incidence}

The patients of both groups had significant different in age; 45.3 and 59.5 years respectively.

\section{Clinical Data}

The degrees of lordosis with the lumbosacral joint angle, the lordosis measurements at L4-L5, L4-L5 disc height, displacement of L4, the laminar inclination angle at L3 had no difference in groups A and $\mathrm{B}$.

Table 1: Parameters of Groups A and B.

\begin{tabular}{|l|l|l|l|}
\hline & \multicolumn{1}{|c|}{$\begin{array}{c}\text { Group A } \\
\mathbf{n} \mathbf{8 6}\end{array}$} & $\begin{array}{c}\text { Group B } \\
\boldsymbol{n}=\mathbf{2 4}\end{array}$ & $\boldsymbol{P}$ \\
\hline Age of patients. & $49.6 \pm 9$ & $62.8 \pm 10$ & 0.05 \\
\hline BMD & $-1.08 \pm 0.21$ & $-1.25 \pm 0.21$ & 0.05 \\
\hline $\begin{array}{l}\text { Angle of Inclination at } \\
\text { L3 Laminae }\end{array}$ & $126 \pm 2$ & $130 \pm 3$ & 0.05 \\
\hline $\begin{array}{l}\text { Lordosis Angle of } \\
\text { Lumbar Spine }\end{array}$ & $23.33 \pm 7.22$ & $26.22 \pm 6.55$ & 0.05 \\
\hline $\begin{array}{l}\text { Lumbosacral Joint } \\
\text { Angle }\end{array}$ & $13.15 \pm 0.33$ & $11.31 \pm .33$ & 0.05 \\
\hline $\begin{array}{l}\text { Disc Space Height of } \\
\text { L4-L5 }\end{array}$ & $1.53 \pm 1.10$ & $1.99 \pm 1.73$ & 0.05 \\
\hline $\begin{array}{l}\text { Lordosis Angle of L4- } \\
\text { L5 }\end{array}$ & $12.65 \pm 0.65$ & $13.40 \pm 1.45$ & 0.05 \\
\hline $\begin{array}{l}\text { Sliding Distance of L4 } \\
\text { Body }\end{array}$ & $1.07 \pm 0.05$ & $0.19 \pm 0.08$ & 0.05 \\
\hline
\end{tabular}


Table 2: Outcomes of Group A and B.

\begin{tabular}{|c|c|c|c|c|c|c|c|}
\hline \multirow{2}{*}{} & \multicolumn{3}{|c|}{ Group A } & \multicolumn{3}{c|}{ Group B } & \multirow{2}{*}{ P } \\
\cline { 2 - 8 } & Pre-operative & At 1 Year & Recovery Rate (\%) & Pre operative & At 1 Year & Recovery Rate (\%) & \\
\hline ODI & $37.7 \pm 6.2$ & $6.6 \pm 2.2$ & $81.1 \pm 26.4$ & $38.9 \pm 6.9$ & $8.2 \pm 8.5$ & $71.7 \pm 19.1$ & 0.05 \\
\hline JOA & $16.3 \pm 3.1$ & $16.3 \pm 4.1$ & $77.4 \pm 26.3$ & $15.3 \pm 1.2$ & $16.9 \pm 2.7$ & $77.2 \pm 16.4$ & 0.05 \\
\hline
\end{tabular}

\section{DISCUSSION}

The degeneration of the lumbar spine is normal aging process. It can present with low back pain, with sensory or motor neurological deficit and sphincter problems. Spinal segment is a mobile segment and carries the weight of the body. After fixation and fusion of any mobile spinal segment, the movements of that segment are compensated at the adjacent segment of the spine leading to adjacent segment disease $^{10}$. If there is an adjacent segment disease, it will require some treatment in the form of $2^{\text {nd }}$ surgery, physiotherapy or medical treatment. It's also proved in another study that spinal decompression with fixation and fusions will alter the biomechanics of spine with more chances of reoperations ${ }^{11}$. We also studied in our study that what leads to adjacent segment disease and why it happens and how it presents and what treatment will be required if it happens. Many spine surgeons are not still clear what causes of ASD are. Only few studies are available that showed that alteration in biomechanics of the spine leads to more movements with increase pressure at the adjacent segment leading to $\mathrm{ASD}^{12}$. Weinhoffer et al, ${ }^{13}$ also proved that fixation and fusions lead to increase in pressure in proximal disc. Sim et al, ${ }^{14}$ proved in their cadaveric study that fusion of the spinal segment leads to more movements on proximal levels in flexion, extension and lateral bendings. Many studies are available in the literature, but no one concluded properly that spinal fusion will lead to the movements problems on adjacent level or will do something with sagittal balance of the spine. Some spine surgeons believe that its alterations in sagittal balance that leads to degeneration and adjacent segment disease ${ }^{15}$. Many spinal surgeons also studied that if proximal disc space is degenerated can it leads to ASD. Some spinal surgeon included proximal degenerative level in fixation also. It is proved in the study that preoperatively proximal degenerative disc disease can cause adjacent segment disease ${ }^{16}$. It is also proved in another study that intrinsic degenerative changes in disc space can cause adjacent segment disease $^{17}$. Many spinal surgeons are including a proximal degenerative segment in fusion and they claim that if degenerative segment not included it can cause adjacent segment disease ${ }^{18}$. Degenerative changes in proximal disc lead to more frequent $\mathrm{ASD}^{19}$. Many of the spinal surgeons come to the conclusion that the proximal preoperative degenerative disc contributes to ASD. Many spinal surgeons believe that screw size, its entry point and orientation should be properly selected. We passed all our screws under flouro guidance with proper orientation and confirmed our screws orientation with the help of CT Scan of lumbar spine with 3D reconstruction. None of our screws violates the proximal fascet nor disc space. In one study, they concluded that if screws violate the inferior fascet of proximal vertebrae then it can lead to adjacent segment disease at that proximal level ${ }^{20}$. This point also concluded in another study if screw damages the inferior fascet then it will alter the biomechanics at that level leading to adjacent segment disease $^{21}$.We studied 110 patients for adjacent segment disease after fixation and fusion at L4-L5 and followup done in one year and radiologically adjacent segment disease at cranial level was seen in $22.18 \%$ of the patients. However, final clinical outcome with reference to ODI and the JOA scores were not statistically different in both groups. Anandjiwala et $\mathrm{al}^{22}$ also proved in their study with 5 years follow up that there are more chances of adjacent segment disease if there are preoperatively more degenerative changes in proximal disc space. In our study, we also confirm that preoperative degenerative changes in proximal disc are a risk factor for ASD at 1 year. The adjacent segment degeneration and adjacent segment disease are not the same entity and adjacent segment disease when symptomatic require $2^{\text {nd }}$ surgery. Instrumented fixation and fusion leads to degeneration at adjacent segment due to alteration in biomechanics $^{23}$. These changes in biomechanics of the 
spine can lead to degenerations in healthy proximal segment post-opertatively ${ }^{24}$. We also studied much other risk factors for adjacent segment disease like age, female sex and rigid instrumentation types. The only significant factor was age of the patient. Older the age more chances of ASD.

Many studies for ASD were limited because they included patients with different diagnosis and use multiple techniques for fixation and fixed different spinal levels. So we included patients with only single level L4 - L5 degeneration and used same fixation techniques in all our patients and used the same implant material and isologous bone graft in all our patients.

\section{CONCLUSION}

We concluded that radiological degeneration of adjacent segment has no significant effect on final clinical outcome after PLIF. Patient's age and inferior fascet violation by screws are important risk factors for adjacent segment disease.

\section{REFERENCES}

1. Ha KY, Schendel MJ, Lewis JL, Ogilvie JW. Effect of immobilization and configuration on lumbar adjacentsegment biomechanics. J Spinal Disord. 1993; 6: 99105. Doi: 10.1097/00002517-199304000-00002.

2. Quinnell RC, Stockdale HR. Some experimental observations of the influence of a single lumbar floating fusion on the remaining lumbar spine. Spine (Phila Pa 1976). 1981; 6: 263-267.

Doi: 10.1097/00007632-198105000-00008.

3. Okuda, S, Iwasaki, M, Miyauchi, A, Aono, H, Morita, M, Yamamoto, T. Risk factors for adjacent segment degeneration after PLIF. Spine (Phila Pa 1976). 2004; 29: 1535-1540.

4. Maragkos GA, Atesok K, Papavassiliou E. Prognostic factors for adjacent segment disease after L4-L5 lumbar fusion. Neurosurgery. Published Online, 2019.

(Doi: 10.1093/neuros/nyz241).

5. Battie MG, Videman T, Parent E. Lumbar disc degeneration: epidemiology and genetics influences. Spine, 2004; 29: 2679-2690.

Doi: 10.1097/01.brs.0000146457.83240.eb.

6. Liao JC, Chen WJ, Chen LH, Niu CC, Keorochana G. Surgical outcomes of degenerative spondylolisthesis with L5 - S1 disc degeneration: comparison between lumbar floating fusion and lumbosacral fusion at a minimum 5-year follow-up. Spine, 2011; 36 (19): 16001607.

7. Lee JC, Kim Y, Soh JW, Shin BJ. Risk factors of adjacent segment disease requiring surgery after lumbar spinal fusion: comparison of posterior lumber interbody fusion and posteriorlateral fusion. Spine, 2014; 39 (5): E339-E345.

8. Lad SP, Babu R, Baker AA, Ugiliweneza B, Kong M, Bagley CA, et al. Complications, reoperation rates, and health-care cost following surgical treatment of lumbar spondylolisthesis. J Bone Joint Surg Am. 2013; 6 (95): e162.

9. Bono CM, Lee CK. Critical analysis of trends in fusion for degenerative disc disease over the past 20 years: influence of technique on fusion rate and clinical outcome. Spine (Phila Pa 1976). 2004; 29 (4): 455-463; Discussion Z455.

10. Ghiselli G, Wang JC, Hsu WK, et al. L5-S1 segment survivorship and clinical outcome analysis after L4-L5 isolated fusion. Spine, 2003; 28: 1275-1280.

11. Forsth P, Michaelsson K, Sanden B. Does fusion improve the outcome after decompressive surgery for lumbar spinal stenosis? A two-year follow-up study involving 5390 patients. Bone Joint J. 2013; 95-B (7): 960-965.

12. Kettler A, Rohlmann F, Ring C, Mack C, Wilke HJ. Do early stages of lumbar intervertebral disc degeneration really cause instability? Evaluation of an in vitro database. Eur Spine J. 2011; 20 (4): 578-584.

Doi: 10.1007/s00586-010-1635-z.

13. Weinhoffer SL, Guyer RD, Herbert M, Griffith SL. Intradiscal pressure measurements above an instrumented fusion. A cadaveric study. Spine (Phila Pa 1976). 1995; 20 (5): 526-531. Doi: 10.1097/00007632199503010-00004.

14. Sim HB, Murovic JA, Cho BY, Lim TJ, Park J. Biomechanical comparison of single-level posterior versus transforaminal lumbar interbody fusions with bilateral pedicle screw fixation: segmental stability and the effects on adjacent motion segments. J Neurosurg Spine, 2010; 12 (6): 700-708.

Doi: 10.3171/2009.12.SPINE09123.

15. Berven S, Wadhwa R. Sagittal alignment of the lumbar spine. Neurosurg Clin N Am. 2018; 29 (3): 331-339. Doi: 10.1016/j.nec.2018.03.009.

16. Tsuji T, Watanabe K, Hosogane N, et al. Risk factors of radiological adjacent disc degeneration with lumbar interbody fusion for degenerative spondylolisthesis. J Orthop Sci. 2016; 21 (2): 133-137.

Doi: 10.1016/j.jos.2015.12.007.

17. Kim H, Kang K, Chun H, Lee C, Chang B, Yeom JS. The influence of intrinsic disc degeneration of the adjacent segments on its stress distribution after onelevel lumbar fusion. Eur Spine J. 2015; 24 (4): $827-$ 837. Doi: 10.1007/s00586-014-3462-0.

18. Wang $\mathrm{H}, \mathrm{Ma} \mathrm{L}$, Yang $\mathrm{D}$, et al. Incidence and risk factors of adjacent segment disease following posterior decompression and instrumented fusion for degenerative lumbar disorders. Medicine, 2017; 96 (5): e6032. Doi: 10.1097/MD.0000000000006032. 
19. Anandjiwala J, Seo JY, Ha KY, et al. Adjacent segment degeneration after instrumented posterolateral lumbar fusion: a prospective cohort study with a minimum five-year follow-up. Eur Spine J. 2011; 20: 1951-60.

20. Liang B, Zhao J, Li N, et al. Surgical treatment of discogenic low back pain by minimally invasive transforaminal lumbar interbody fusion combined with unilateral pedicle screw fixation. Zhongguo Xiu Fu Chong Jian Wai Ke Za Zhi. 2012; 26: 272-6.

21. Maruenda JI, Barrios C, Garibo F, et al. Adjacent segment degeneration and revision surgery after circumferential lumbar fusion: outcomes throughout 15 years of follow-up. Eur Spine J. 2016; 25: 1550-7.

22. Anandjiwala J, Seo JY, Ha KY, et al. Adjacent segment degeneration after instrumented posterolateral lumbar fusion: a prospective cohort study with a minimum five-year follow-up. Eur Spine J. 2011; 20: 1951-60.

23. Ruberte LM, Natarajan RN, Andersson GB. Influence of single-level degenerative lumbar e disc disease on the behavior of the adjacent segments - a finite element model study. J Biomech. 2009; 42: 341-8.

24. Liang J, Dong Y, Zhao H. Risk factors for predicting symptomatic adjacent segment degeneration requiring surgery in patients after posterior lumbar fusion. J Orthop Surg Res. 2014; 9: 97.

25. World Health Organisation. Obesity: Preventing and Managing the Global Epidemic. Geneva: World Health Organisation, 1997.

26. Guigui P, Lambert P, Lassale B, De- burge A. Long term outcome at adjacent levels of lumbar arthrodesis. Rev Chir Orthop Reparatrice Appar Mot. 1997; 83: 685-696.

\title{
Additional Information
}

Disclosures: Authors report no conflict of interest.

Ethical Review Board Approval: The study was conformed to the ethical review board requirements.

Human Subjects: Consent was obtained by all patients/participants in this study.

Conflicts of Interest:

In compliance with the ICMJE uniform disclosure form, all authors declare the following:

Financial Relationships: All authors have declared that they have no financial relationships at present or within the previous three years with any organizations that might have an interest in the submitted work.

Other Relationships: All authors have declared that there are no other relationships or activities that could appear to have influenced the submitted work.

\author{
Address for Correspondence: \\ Dr. Ijaz Wadd \\ Email:drejazns@gmail.com
}

\section{AUTHORSHIP AND CONTRIBUTION DECLARATION}

\begin{tabular}{|l|l|l|l|}
\hline Sr.\# & Author's Full Name & Intellectual/Contribution to Paper in Terms of: \\
\hline 1. & Ijaz Hussain Wadd & 1. Main investigator/ data collection. \\
\cline { 1 - 2 } 2. & Liaqat Mehmood Awan & 2. Data analysis and report writing \\
\cline { 1 - 2 } 3. & Syed Mohsin Ajmal & 3. Data analysis and report writing \\
\cline { 1 - 2 } 4. & Asif Shabir & 4. Co investigator and data collector. \\
\cline { 1 - 2 } 5. & Humaira Mushtaq & 5. Literature review and Manuscript writing \\
\cline { 1 - 2 } 6. & Rizwan Masood Butt & 6. Analysis of data and quality insurance \\
\hline
\end{tabular}

Date of Submission: $20-3-2020$

Date of Revision: 12-04-2020
Date of Online Publishing: 30-06-2020

Date of Print: 30-07-2020 